can be prepared for but not avoided. Health organizations and government agencies across the world must develop a disaster readiness mindset so that even though COVID-19 is mutating ${ }^{9}$ and the looming possibility of future pandemics is constant, ${ }^{10}$ the damage of these disasters can become better predicted, prevented, and controlled.

Acknowledgments. The authors thank the editor and reviewers for their constructive input.

Financial support. No financial support was provided relevant to this article.

Conflicts of interest. All authors report no conflicts of interest relevant to this article.

\section{References}

1. Ricciardi A, Palmer ME, Yan ND. Should biological invasions be managed as natural disasters? BioScience 2011;61:312-317.
2. Adger WN, Hughes TP, Folke C, Carpenter SR, Rockström J. Social-ecological resilience to coastal disasters. Science 2005;309:1036.

3. Su Z, McDonnell D, Ahmad J, et al. Time to stop the use of 'Wuhan virus', 'China virus' or 'Chinese virus' across the scientific community. BMJ Glob Health 2020;5(9):e003746.

4. COVID-19 and racism—a double edged dagger. Lancet Diabetes Endocrinol 2020;8:649.

5. Renda A, Castro R. Towards stronger EU governance of health threats after the COVID-19 pandemic. Eur J Risk Regul 2020;11:273-282.

6. White DB, Lo B. A framework for rationing ventilators and critical care beds during the covid-19 pandemic. JAMA 2020;323:1773-1774.

7. Grove T. Beneath Helsinki, Finns prepare for Russian threat. The Wall Street Journal. July 14, 2017.

8. Anderson C, Libell HP. Finland, 'Prepper nation of the Nordics,' Isn't worried about masks. New York Times. April 5, 2020.

9. Grubaugh ND, Hanage WP, Rasmussen AL. Making sense of mutation: What D614G means for the COVID-19 pandemic remains unclear. Cell 2020;182:794-795.

10. Honigsbaum M. Disease X and other unknowns. Lancet 2019; 393: 1496-1497.

\title{
Coronavirus disease 2019 (COVID-19) era hospital infection controls reduce other serious infections and must be continued after the COVID-19 tragedy is resolved
}

\author{
Luke Curtis MD, MS, CIH, CMPP (1) \\ Curtis Research, Hazelwood, Missouri
}

To the Editor-I read with great interest your 3 recent papers by Wong et $\mathrm{al}^{1}$ Ponce-Alonso et $\mathrm{al}^{2}$, and Wee et al, ${ }^{3}$ who report that coronavirus disease 2019 (COVID-19)-era infection control bundles are associated in significant decreases in many nosocomial viral and bacterial infection rates such as influenza, respiratory syncytial virus, adenovirus, and Clostridium difficile. The Ponce-Alonso Spanish study reported a decrease of $69 \%$ in hospital-acquired Clostridium difficile infection rates following implementation of a hospital infection control bundle: incidence density was 8.54 per 10,000 patients day before and 2.68 per 100,000 days after the COVID-19 infection control bundle $\left(P=.000257^{2}\right)$.

Other studies have also reported that COVID-19-era infection controls such as hand washing, masking and gowning, better hospital cleaning, and isolation of COVID-19 patients can significantly reduce rates of many bacterial and viral infections. A study in a 1,785-bed Singapore hospital reported that the use of COVID-19-related infection control bundles was associated with significantly reduced rates of many hospital-acquired infections, including nosocomial respiratory infections (incidence rate, 0.08 ; 95\% CI, 0.05-0.13), nosocomial MRSA (IR, 0.54; 95\% CI, 0.460.64 ), and central-line bloodstream infections (IR, 0.24; $95 \% \mathrm{CI}$,

Author for correspondence: Luke Curtis, E-mail: LukeCurtis1328@gmail.com

Cite this article: Curtis L. (2022). Coronavirus disease 2019 (COVID-19) era hospital infection controls reduce other serious infections and must be continued after the COVID19 tragedy is resolved. Infection Control \& Hospital Epidemiology, 43: 539-540, https:// doi.org/10.1017/ice.2021.11
0.07-0.57). ${ }^{4}$ A California study involving 37,033 hospital patient days reported that following implementation of a COVID-19 infection control bundle, rates of many multidrug-resistant pathogens decreased significantly including a $41 \%$ decrease in methicillin-resistant Staphylococcus aureus (MRSA), a 21\% decrease in (extended-spectrum $\beta$-lactamase bacteria (ESBL), and an $80 \%$ decrease in vancomycin-resistant enterococci (VRE). ${ }^{5}$

Better hospital infection control bundles can also reduce rates of common nosocomial fungal infections, ${ }^{6}$ although I am not aware of any current studies that have reported on lower rates of Aspergillus or Candida in the COVID-19 era. Such studies of COVID-19-era nosocomial Aspergillus and Candida rates might yield useful data on how to prevent common life-threatening fungal infections.

Clearly, enhanced infection control procedures need to be followed long after the COVID-19 tragedy has resolved. ${ }^{7}$ I hope that Infection Control and Hospital Epidemiology will continue to publish more good papers on COVID-19-era infection control.

\section{Acknowledgments.}

Financial support. No financial support was provided relevant to this article.

Conflicts of interest. The author reports no conflicts of interest relevant to this article. 


\section{References}

1. Wong SC, Lam GK, AuYeung CH, et al. Absence of nosocomial influenza and respiratory syncytial virus infection in the coronavirus disease 2019 (COVID-19) era: Implication of universal masking in hospitals. Infect Control Hosp Epidemiol 2020. doi: 10.1017/ice.2020.425.

2. Ponce-Alonso M, Sáez de la Fuente J, Rincón-Carlavilla A, et al. Impact of the coronavirus disease 2019 (COVID-19) pandemic on nosocomial Clostridioides difficile infection. Infect Control Hosp Epidemiol 2020. doi: 10.1017/ice.2020.454.

3. Wee LE, Conceicao EP, Sim JXY, Aung MK, Venkatachalam I. Impact of infection prevention precautions on adenoviral infections during the COVID-19 pandemic: experience of a tertiary hospital in Singapore. Infect Control Hosp Epidemiol 2020. doi: 10.1017/ice.2020.1365.
4. Wee LEI, Conceicao EP, Tan JY, et al. Unintended consequences of infection prevention and control measures during COVID-19 pandemic. Am J Infect Control 2020. doi: 10.1016/j.ajic.2020.10.019.

5. Cole J, Barnard E. The impact of the COVID-19 pandemic on healthcare acquired infections with multidrug-resistant organisms. Am J Infect Control 2020:5726. doi: 10.1016/j.ajic.2020.09.013.

6. Suleyman G, Alangaden GJ. Nosocomial fungal infections: epidemiology, infection control, and prevention. Infect Dis Clin NA 2016;30: 1023-1052.

7. Cerulli Irelli E, Morano A, Di Bonaventura C. Reduction in nosocomial infections during the COVID-19 era: a lesson to be learned. Updates Surg 2020. doi: 10.1007/s13304-020-00925-0.

\title{
The other ' $C$ ': Hospital-acquired Clostridioides difficile infection during the coronavirus disease 2019 (COVID-19) pandemic
}

\author{
Karl Hazel MB, BCh, BAO BA(mod), MRCPI ${ }^{1}$ (1) Mairead Skally $\mathrm{MSc}^{2}$, Emily Glynn MB ${ }^{1}$, Margaret Foley $\mathrm{MSc}^{3}$, \\ Karen Burns $\mathrm{MSc}^{2,3}$, Aoibhlinn O'Toole $\mathrm{MD}^{1}$, Karen Boland $\mathrm{PhD}^{1}$ and Fidelma Fitzpatrick $\mathrm{MD}^{2,3,4}$ \\ ${ }^{1}$ Department of Gastroenterology, Beaumont Hospital, Dublin 9, Ireland, ${ }^{2}$ ESCMID Study Group for Clostridioides difficile, ${ }^{3}$ Department of Microbiology, \\ Beaumont Hospital, Dublin 9, Ireland and ${ }^{4}$ Department of Clinical Microbiology, Royal College of Surgeons in Ireland, Dublin 9, Ireland
}

To the Editor-We read with interest the recent article by LeRose et $\mathrm{al}^{1}$ on the impact of coronavirus disease 2019 (COVID-19) on healthcare-associated infection. In contrast to their observations of increased central-line-associated infection and blood-culture contamination rates during the first wave of the COVID-19 pandemic, we observed a decrease in hospital-acquired Clostridioides difficile infection (HA-CDI) within our institution over this time, compared with the same period in previous years.

CDI is the leading cause of hospital-acquired infectious diarrhea. Risk factors include older age, comorbidities, and most notably, broad-spectrum antibiotic use. ${ }^{2}$ High bed occupancy in acute-care hospitals correlates with an increased incidence of healthcare-associated CDI (HA-CDI). ${ }^{3}$ The COVID-19 pandemic has caused significant changes within the healthcare system worldwide. In hospitals, the cessation of elective procedures in early March combined with an overall reduction in emergency presentations for non-COVID-19-related illnesses led to a reduction in hospital occupancy rates from March to May 2020. ${ }^{4}$ Concern has been expressed that COVID-19 may impact CDI rates, especially in the elderly. ${ }^{5}$ Older people with comorbidities are disproportionately affected by COVID- $19 .{ }^{6}$ Concurrent broad-spectrum antimicrobials to treat bacterial co-infection and super-infections in COVID-19 may also increase the risk of CDI. ${ }^{7}$ Conversely, the increased focus on infection prevention and control may prevent cross transmission of C. difficile.

We hypothesized that the infection prevention and control measures implemented in our institution to prevent COVID-19

Author for correspondence: Karl Hazel, MB, Department of Gastroenterology, Beaumont Hospital, Dublin 9, Ireland. E-mail: karl.hazel@gmail.com

Cite this article: Hazel K, et al. (2022). The other 'C': Hospital-acquired Clostridioides difficile infection during the coronavirus disease 2019 (COVID-19) pandemic. Infection Control \& Hospital Epidemiology, 43: 540-541, https://doi.org/10.1017/ice.2021.3 transmission would also influence HA-CDI. These measures included a hospital-wide transmission-based-precautions educational program, increased focus on hand hygiene compliance and audit, social distancing, and reduced ward occupancy.

Our institution is an adult tertiary-care referral center with $>800$ beds and 136 single rooms ( $77 \%$ with en suite facilities) and 12 airborne isolation rooms. Most accommodation is multioccupancy; comprising 6-, 4- or 2-bed rooms and shared bathroom. We defined the first COVID-19 wave in our institution as March 1 to May 31, 2020. The first positive inpatient with COVID-19 was admitted on March 10, 2020. Daily on-site SARS-CoV-2 real-time polymerase chain reaction (PCR) testing commenced on March 16 for patients with suspected COVID19 and for all admitted patients on April 19. ${ }^{8}$ Daily onsite C. difficile laboratory testing continued without interruption during the first COVID-19 wave. This involves a 2-step protocol: testing for $C$. difficile toxin $\mathrm{B}$ gene $\mathrm{tcdB}$ by $\mathrm{PCR}$ and if positive, testing for $C$. difficile toxin. Positive results are reported by telephone daily by the clinical microbiologist, who also discusses relevance and recommended management plans. Patients are isolated with contact precautions, and on discharge, hydrogen peroxide decontamination of the area is performed prior to new patient admission.

Data on newly acquired HA-CDI from March 1 to May 31 were collected and compared to the same periods in 2018 and 2019. CDI data were extracted from the hospital CDI database. This database comprises CDI data, which are collected and validated prospectively, with assignment of CDI case type as outlined in national guidelines. ${ }^{9}$ Patient demographics and biochemical markers were collected from the patient administration systems. Hospital antimicrobial consumption and hand hygiene audit data for the same periods were also collected. One-way ANOVA using Prism software (GraphPad, San Diego, CA) was employed to determine whether there was a statistically significant difference between

(C) The Author(s), 2021. Published by Cambridge University Press on behalf of The Society for Healthcare Epidemiology of America This is an Open Access article, distributed under the terms of the Creative Commons Attribution licence (http://creativecommons.org/licenses/by/4.0/), which permits unrestricted re-use, distribution, and reproduction in any medium, provided the original work is properly cited. 